In the Realm of Mind:

Nine Chapters on the Applications and Implications of Psychology. By Dr. Charles S. Myers. Pp. v+251. (Cambridge: At the University Press, 1937.) 7s. 6d. net.

THE appearance of a further volume of semi-popular papers on psychological subjects by Dr. C. S. Myers, just before the recent meeting of the British Association, was an inevitable reminder of the part he has played in securing the recognition of psychology as one of the sciences. As far back as 1913, it was so recognized by the British Association to the extent of its being made a sub-section under physiology. Not until 1920 was it accorded the rank of a section, and from 1922 to 1931 Dr. Myers was president of that Section.

It is fortunate for a subject which has been calledeven by one of its distinguished representativesno science but only the hope of a science, that so true a man of science as Dr. Myers has had a large share in guiding its destinies. His great work, not only as an experimental psychologist, but also as our national leader in the practical application of psychology to industrial and other problems, is too well known to call for special remark in this place. Readers of his former volume entitled "A Psycho. logist's Point of View" will not be likely to miss this new collection of papers. They cover a variety of topics-the choice of a career, the human factor in accidents, medical education, social psychology, internationalism, psychological conceptions in other sciences, and the nature of mind. But all this variety is consistent with a unity which comes of a common point of view. This is just the kind of book and just the kind of treatment calculated to convince any reasonable person that psychology is unquestionably a science.

(I) Biochemistry Applied to Malting and Brewing By Prof. R. H. Hopkins and B. Krause. Pp. 342. (London: George Allen and Unwin, Ltd., 1937.) 12s. $6 d$. net.

(2) Practical Management of Pure Yeast :

the Application and Examination of Brewery, Distillery and Wine Yeasts. By Alfred Jörgensen. Third edition, revised by Albert Hansen. Pp. xii + 111. (London: Charles Griffin and Co., Ltd., 1936.) 68.

MANY famous names in the past have established the tradition that chemical research is an essential part of brewing practice. It is desirable, therefore, that a proper training in biochemistry should form the basis of the education of the would-be brewer and that the text-books available for the students be of high standard.

(l) The book under notice is largely a translation from the Danish of a book by Krause to which Prof. Hopkins has given an English aspect. It falls into two sections-one chemical, the other largely practical. The former is on the whole unsatisfactory, though the difficulty of compressing the necessary chemistry into a few pages must be allowed for. Probably it is best to separate the two subjects and teach the student his chemistry on orthodox lines. The more practical portion written by a man who knows his subject is excellent : the work should prove useful.

(2) In the yeast field the name of Jörgensen of Copenhagen stands high : no one has done more for the subject in practice and as a teacher. A third edition of his little practical handbook, revised by A. Hansen, is assured of a welcome.

\section{Military Engineering}

Vol. 6: Water Supply. (War Office.) Pp. 421+171 plates. (London: H.M. Stationery Office, 1937.) 10s. net.

THE volume on water supply, issued as a manual by the War Office, is a comprehensive survey of the subject in which, naturally, predominance is assigned to those aspects of the matter which affect military operations. At the same time a very useful summary is given of general principles, and the essential facts relating to water supply, whether civil or military, are set out with commendable directness and precision. There are fifteen chapters, covering water supply requirements ; reconnaissance of sources and measurements of yield; well-sinking and -boring; reciprocating and centrifugal pumps; water elevators and pumping by compressed air ; selection, installation and operation of pumping plant; storage; water analysis ; principles of water purification; water purification practice; distributing systems, water points and water transport; field supplies during mobile operations; field supplies during protracted operations; water supply calculations and examples of camp supplies. A number of tables, plates and figures, with seven appendixes and an index, help to make up a very serviceable manual for general use.

In the compilation within reasonable limits of such a variety of information, there is naturally scope for difference of opinion on certain points, such as the statement on p. 42 that "in searching for suitable sites for shallow wells and tube wells, the employ. ment of dowsers, or water diviners, may save time and possibly fruitless labour in well sinking". B. C.

\section{Health and a Day:}

Addresses. By Lord Horder. Pp. viii +213. (London : J. M. Dent and Sons, Ltd., 1937.) 7s. 6d. net.

ThIs volume consists of twelve addresses delivered during the last two years before medical and lay audiences in Great Britain and the United States. Six of the addresses were given before medical gatherings, but only two, entitled "The Clinician's Function in Medicine" and "Direct Action in Medicine", were specially intended for the medical profession. Other addresses deal with the strain of modern civilization, the doctor as humanist, the doctor's place in society, the Hunterian tradition, national health, old diseases and new, and euthanasia. Although several of the addresses have been published before, the pleasant conversational style, and the eminently sane opinions expressed by one of the most distinguished London physicians, should secure for the work a wide circle of readers. 